\title{
Reviewing the RCM on Cooling Water Pump of LNG Production Company
}

\author{
Shaneza Fatma Rahmadhanty ${ }^{1}$, Trika Pitana ${ }^{2}$, Nurhadi Siswantoro ${ }^{3}$
}

(Received: 02 February 2019 / Revised: 26 March 2019 / Accepted: 26 March 2019)

\begin{abstract}
A company, such as LNG production company, must be able to produce and meet energy needs independently to support all operations, such as cooling water system that functions to control the temperature and pressure so that the production process runs optimally. If this system is disrupted, there will be excess use of water, wastewater, and energy costs needed which result in higher total operational costs. With good and right care, it can reduce all risks posed. One component that plays a role in the cooling water system is a pump. This pump serves to flow the cooling water which is seawater to the LNG industry plant. At present, the amount of Work Order data recorded from the problems obtained from the pump requires maintenance updates. In this study, the method in the maintenance programs is used based on the Reliability-Centered Maintenance (RCM) implementation. RCM will increase cost efficiency, reliability, pump uptime, and propose maintenance tasks. Beside the pump, the reviewing also involve supports components that affect pump optimization. In this paper, the functions, causes, and effects are identified, and the new scheduled maintenance tasks are shown.
\end{abstract}

Keywords - Cooling Water Pump, FMEA, Maintenance, RCM

\section{INTRODUCTION}

I recent decades, humans have begun to think about acquiring new energy sources as a substitute for energy sources that are widely known and used, such as petroleum and coal because the availability of these energy sources in the natural world is decreasing and has been proven to cause pollution to the environment. This is very undesirable because it will cause greater damage to nature. Various efforts have been made to obtain substitute energy sources that can meet energy needs in the large and long term and are environmentally friendly. One of the energy sources that are currently in demand is natural gas. Natural gas, as well as petroleum, is a mixture of hydrocarbon compounds formed from heaps of organic fossils that have been in the bowels of the earth for millions of years ago. To overcome the problem of storage and transportation to consumers, liquefaction of natural gas is considered the best way. In this way, natural gas can be stored 1/600 smaller than its volume in a gas state. In principle, this technology includes liquefaction of natural gas by using refrigerants. This liquefied natural gas is called Liquified Natural Gas (LNG) [1].

Nowadays, there are many LNG production companies that support the LNG business. For the efficiency of the production process, most industries provide cooling water system to control temperature and pressure by transferring heat of hot fluid from the production process into the cooling water system. The

Shaneza Fatma Rahmadhanty, Hochschule Wismar, University of Applied Sciences Technology Business and Design, Wismar, Germany, Email: shanezafatma@gmail.com

Trika Pitana, Departmen of Marine Engineering, Institut Teknologi Sepuluh Nopember, Surabaya 60111, Indonesia, Email: trika@its.ac.id Nurhadi Siswantoro, Departmen of Marine Engineering, Institut Teknologi Sepuluh Nopember, Surabaya 60111, Indonesia, Email: nurhadi@ne.its.ac.id cooling water system is a very important part because in this process the cooling water system will receive heat and needs to be cooled again or replaced with new water from make-up water. In the world of industry, cooling water system is one of the system/equipment that must be kept operational with routine maintenance in order to work optimally. Inadequate cooling water quality control causes excessive use of water, wastewater, and energy costs, resulting in higher total operational costs. An example is a machine as a heat exchange unit, it will experience corrosion or crust formation. The heat exchanger that undergoes corrosion causes the level of efficiency of the low heat transfer system and causes considerable energy consumption [2].

One component that influences the Cooling water system is a pump. This pump serves to flow the fluid of cooling water in the form of sea water to the LNG plant industry. However, currently, problems with the cooling water pump often occur. This can be evidenced by the WO (Work Order) data recorded from the problems obtained from the pump. Therefore, to reduce the risk of failures at the pump, the implementation of ReliabilityCentered Maintenance (RCM) is implemented. However, with pump conditions in this period that have been different compared to the previous conditions, RCM updates are needed [3].

Reliability-Centered maintenance (RCM) is a process used to determine what must be done to ensure that any physical asset continues to do what its users want it to do in its present operating context. RCM is used to develop a maintenance plan with a certain level of operation, with a certain level of risk, which is efficient and price effective [4]. The minimum criteria for conducting an RCM analysis, in general, is by answering the following seven questions:

1. What are the functions and associated performance standards of the asset in its present operating context?

2. In what ways does it fail to fulfil its functions?

3 . What causes each functional failure?

4. What happened when each failure occurs?

5. In what way does each failure matter? 
6. What can be done to predict or prevent each failure?

7. What should be done if a suitable proactive rask cannot be found?

From the results of this study, it will be found the suitable maintenance tasks and maintenance strategies that will reduce the risk. It is expected that this study can increase LNG production by implementing the maintenance techniques strategy in the cooling water pump.

\section{METHOD}

The research in this opportunity is using a case study of one of the LNG production company that experiences many failures of cooling water pumps. In order to achieve this objective, several steps have to be taken into account. The step that the author used references to the workshop presentation of Maintenance \& Production Reliability Conference (MAPREC) 2005 by Dwi Priyanta [2]. The flowchart of the methodology can be shown in Figure 1.

The explanation of this figure is the first is identification problems that identifies the problems begins by identifying and analyzing the objects to form a research title that is expected to contribute to the major of Marine Engineering. The second is system selection and data collection that got by collecting the data of Work Order, PFD (Process Flow Diagram), P\&ID (Pipe \& Instrument Diagram), task list of PM (Preventive Maintenance) \& PDM (Predictive Maintenance), pump technical data and the supporting components, and Cooling Water Utilities Manual Book by Team Task Force "Pembuatan Operational Manual" [3]. To support this study, the author visited the cooling water plant directly. The third is the system boundary definition, which defines the precise boundaries that must be identified for the RCM analysis process.

The system boundary is determined from Travelling Screen to Amri Valve. The fourth is system description and making a functional block diagram that represents how they interact with each other. The fifth is making the FMEA/The RCM Information Worksheet which will then analyzed for failures based on function, functional failure, failure mode, and failure effect. And the last is making The RCM Decision Worksheet. This worksheet needs to answer the RCM Decision Diagram which consists of failure consequences and the maintenance task techniques. By doing this, the maintenance tasks are determined whether it must use proactive tasks such as scheduled restoration task, scheduled discard task, scheduled on-condition task or default action like the redesign, failure finding, and no scheduled maintenance. With this step, the initial interval of the proposed maintenance task is found. If the result is good, it can continue to make a conclusion and report. If not, it must go back to study the literature or discussion with the expert.

\section{RESULT AND DISCUSSION}

\section{A. System Selection and Data Collection}

The objects that will be reviewed include Travelling Screen, Pump, Lubricating System, Boving Valve,
Hayward Strainer, and Amri Valve. The simplified cooling water line is shown in Figure 2. While the system selection is used to identify what and why the objects should be analyzed. Here is the result of system selection:

- System ID : $32 \mathrm{G}$

- Name : Cooling water pump

- Function: The equipment should provide cooling water into the process trains E-G, the utilities, and storage \& loading of module II. With the capacity of 65000 GPM and the head of $200 \mathrm{ft}$. To fulfill the duty, 12 cooling water pumps are provided. Every pump has interconnection to connect each other so that if a pump failed, the other pump can replace it.

- Analysis reason: At this time, the data recorded in the Work Order is increasing. This indicates that the previous RCM is invalid.

\section{B. System Boundary Definition \& Detail}

Precise boundary definition is important in the RCM process due to factor in establishing what comes into the system and what has or has not been included in the system so that potentially important functions are not inadvertently neglected.

- System ID: $32 \mathrm{G}$

- Name: Cooling water pump

- Major equipment included: Bearing, Motor, Impeller, Gasket, Shaft, Coupling, Casing, Foundation, Seal, Packing, Suction Cover.

- Primary physical boundary: Start with Basin and terminate with $\emptyset 84$ inch pipes after Amri Valve.

- Bounding System: Cooling water

- Type of Interface: IN \& OUT

- Interface Location

Pump suction inlet (for IN) \& pump discharge outlet (for OUT)

\section{Functional Block Diagram}

Functional Block Diagram is helpful to clarify the operating. This diagram shows all the primary functions of an enterprise at any given level. The functional block diagram is presented in Figure 3. From this figure, it can be known the flow of cooling water, lubricating oil, hydraulic oil for Boving Valve, and hydraulic oil for Amri Valve. The flow of this cooling water system is sea water passes through the basin that accommodates cooling water to be clean enough from the impurities contained in it and the disinfectant is added to the basin to weaken the activity of bacteria and microorganisms. After that, the sea water passes Traveling Screen to be filtered again from smaller impurities. And then continued to the pump, and the Boving Valve works by preventing the return flow to the side of the pump suction. The lubricating system functions to lubricate the pump so that the pump. Then the cooling water will be filtered with a smaller filter than the Traveling Screen filter on the Hayward Strainer to be forwarded to the industrial plant. If the pump needs to stop/standby or is being repaired, the pump will be isolated by the Amri Valve. 
International Journal of Marine Engineering Innovation and Research, Vol. 3(3), Mar. 2019. 109-117 (pISSN: 2541-5972, eISSN: 2548-1479)

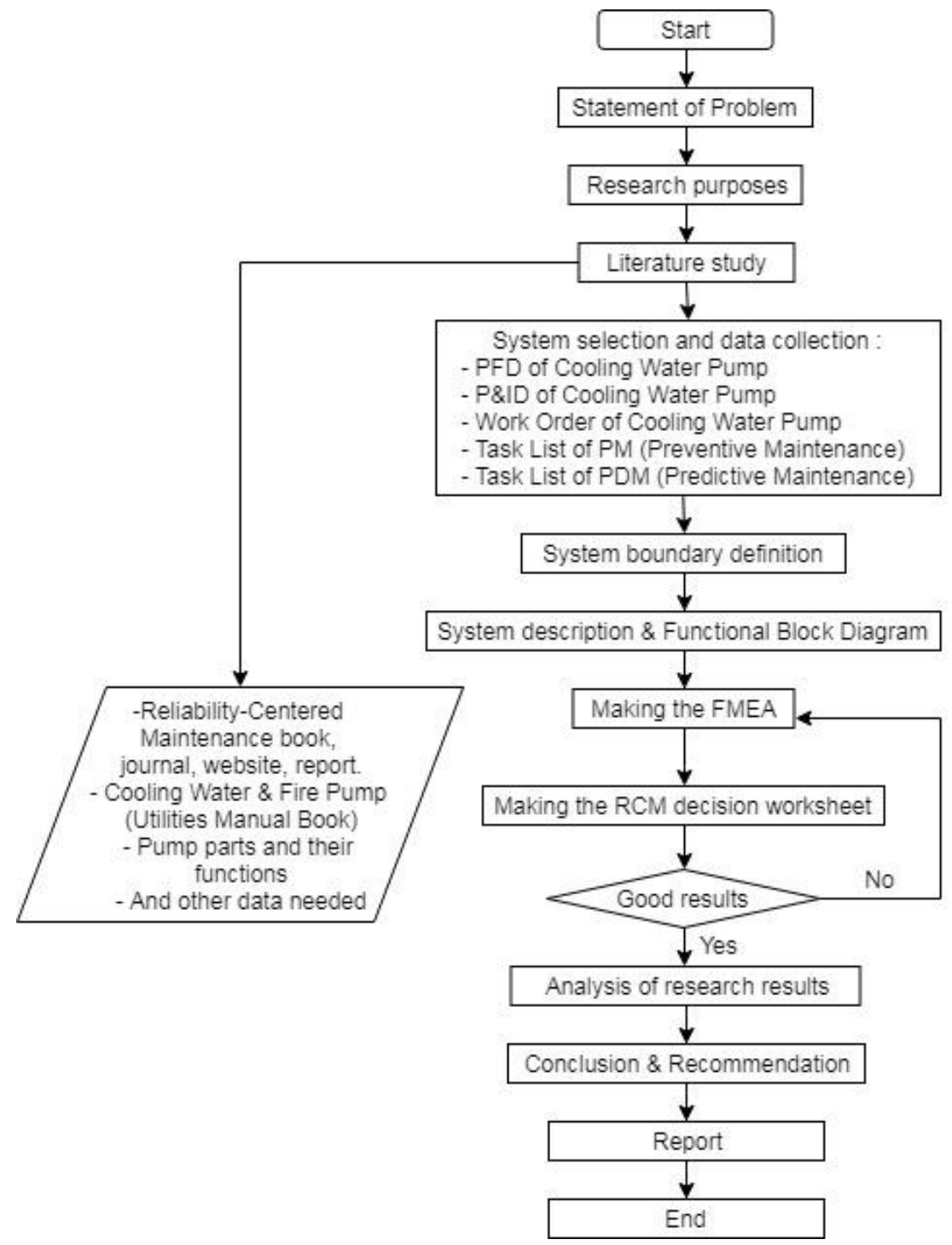

Figure. 1. The flowchart of methodology

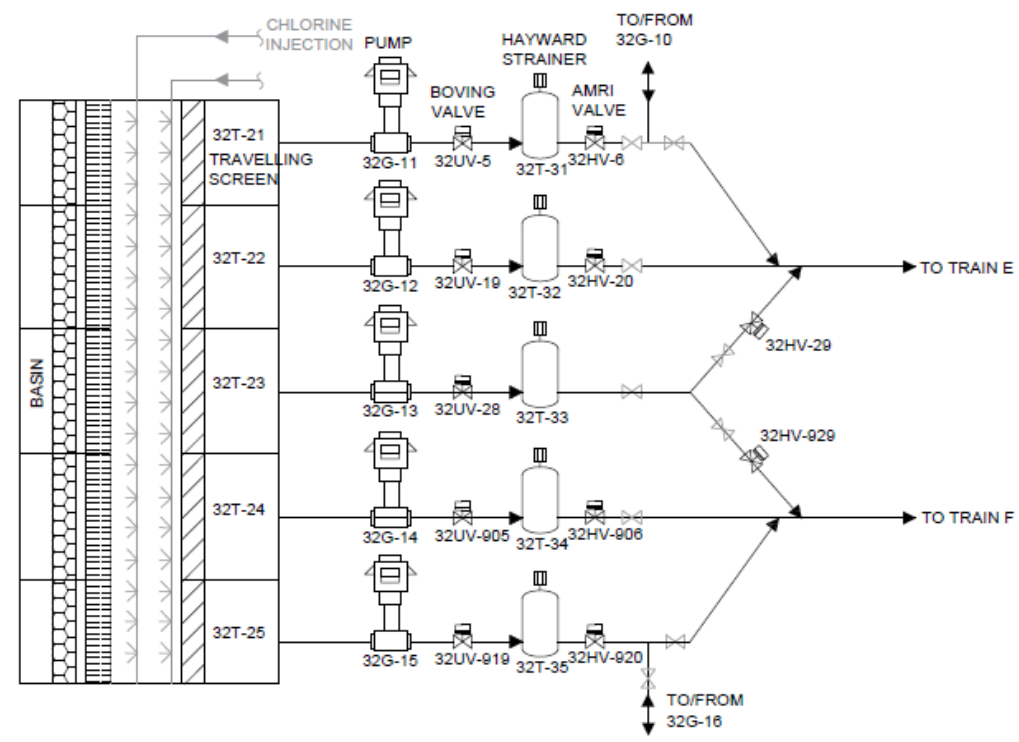

Figure. 2. The simplified cooling water line 


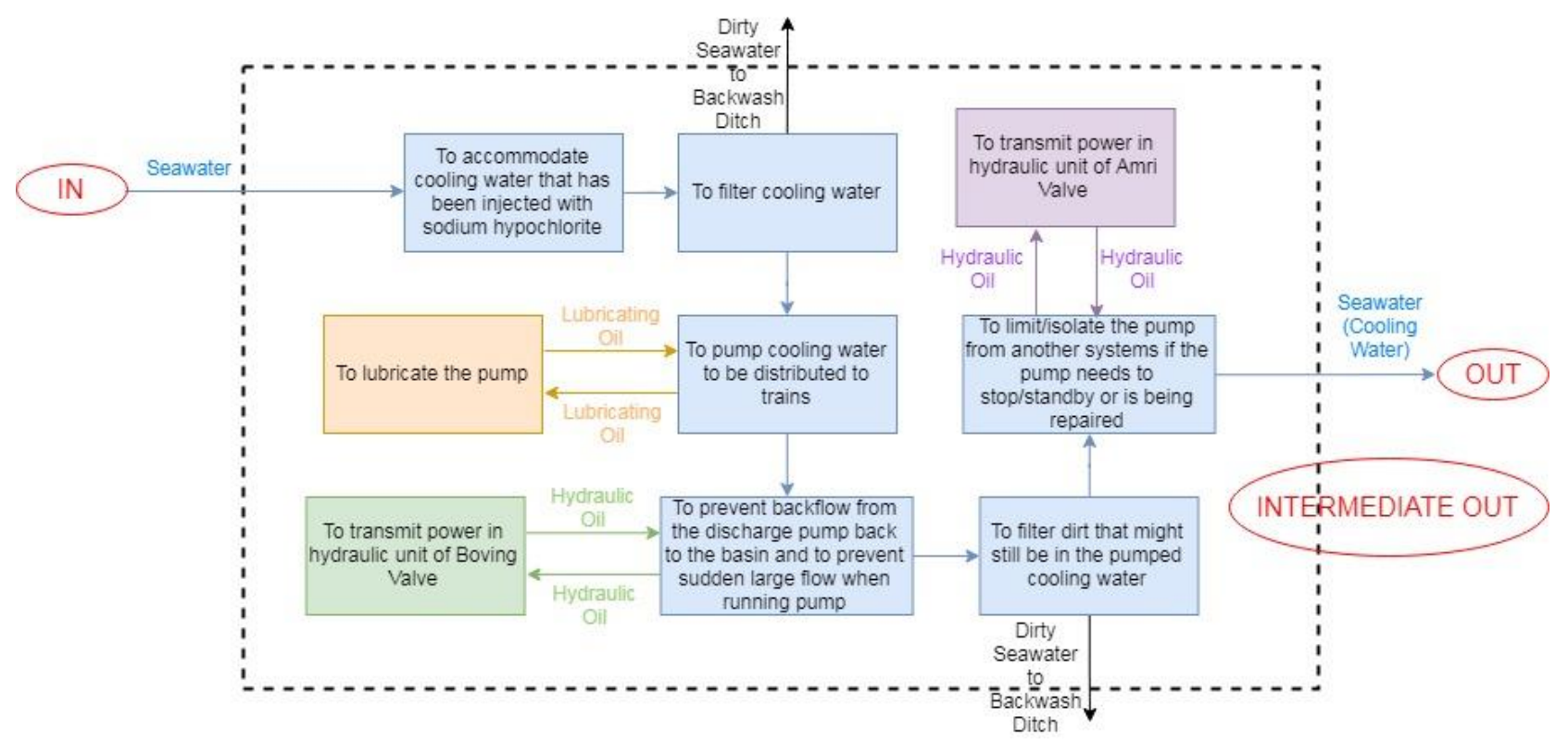

Figure. 3. The functional block diagram

\section{1) Making the FMEA}

FMEA needs to define functions, functional failure, failure mode, and failure effects of components reviewed. Here is the result of the analysis:

\section{a) Defining Functions}

The function is what the asset must do in order to make the system run properly as the users want. A function statement consists of a verb, an object, and the desired standard of performance [1]. Functions are categorized into 2 types:

\section{Primary Function}

The Primary function is the main reason why the asset is acquired.

\section{Secondary Function}

The secondary function is more functions in addition to their primary functions of most assets.

From this study case, the function is:

To distribute the cooling water with the capacity of $65000 \mathrm{GPM} 914763 \mathrm{~m}^{3} / \mathrm{hr}$ ) and the head of $200 \mathrm{ft}(61 \mathrm{~m})$.

\section{b) Functional Failure}

In the world of RCM, failed states are known as functional failures because they occur when an asset is unable to fulfill a function to the standard of performance which is acceptable to the user. In general, each function must have at least two functional failures. This part is to answer the second question of the RCM. A functional failure can be a complete loss of function or partial loss of function. The partial loss of function is usually represented by deviations in the performance standard.

From this study case, the functional failures are:

(a) Total loss of function
- No flow of cooling water

(b) Partial loss of function

- Flow less than 65000 GPM

- Flow more than 65000 GPM

- Head pump less than $200 \mathrm{ft}$

- Head pump more than $200 \mathrm{ft}$

\section{c) Failure Modes and Effect Analysis}

By performing a failure modes and effects analysis (FMEA), it can answer the two questions that sought to identify the failure modes which are reasonably likely to cause each functional failure and to ascertain the failure effects associated with each failure mode [4].

Failure Mode could be defined as the inability to fulfills functions. The examples of a failure mode are deterioration, lubrication failures, dirt, disassembly, etc.

For failure modes, the author takes a reference from the list of failures in the Work Order of the Cooling Water Pump, Pump User's Handbook: Life Extension by Heinz P. Bloch 2010 [5], Pumping Manual book by T. C. Dickenson 1995 [6], Centrifugal Pump User's Guidebook by Sam Yedidah 1996 [7], Bearing Failure: Cause and Cures bu The Barden Corporation 2011 [8], and Failure Mode/Mechanism Distributions by Reliability Analysis Center 1991 [9]. In addition, a discussion with the expert also done. The example of failure modes is:

(a) No Flow of cooling water: Bearing failure, seal failure, shaft failure, electric motor overheat, excessive vibration, blockages.

(b) Flow less than 65000 GPM: Cavitation, impeller failure, gasket failure, seal failure, bearing failure, shaft failure, pressure pulsation, suction and discharge recirculation, excessive vibration, blockages. 
(c) Flow more than 65000 GPM: Excessive power consumption, excessive power resources, electric motor failure.

(d) Head pump less than $200 \mathrm{ft}$ : Cavitation, impeller failure, gasket failure, seal failure, bearing.

(e) Failure, shaft failure, pressure pulsation, sucttion and discharge recirculation, excessive vibration, blockages, reduction in pump pressure.

(f) Head pump more than $200 \mathrm{ft} \quad$ :

Excessive power consumption, excessive power resources, electric motor overheat.

While the Failure Effect is what happens when a failure mode occurs. The effect can be the local effect when the failure mode occurs, it affects the asset just for the early times it occurs, or it can end effect when the failure mode occurs continuously until it affects the whole system or sometimes the whole plant. The results of the failure effects of each failure modes are:

- Bearing failure: will cause leakage/pump efficiency to be low. Cooling water pressure pumped by the operational pump is not optimal. In a long time, it will cause the pump trip.

- Blockages: damage to the pump, because the pump operates but no fluid is sucked. The pump will trip. To fix it will make operational delay.

- Cavitation: excessive noise. Cause pump efficiency to be low. The pumped cooling water pressure drops so that the pump suction level also falls. The operational pump is not optimal.

- Electric motor failure: electric overheat motors, to fix it will make operational delay.

- Electric motor overheat: material expansion, deformation, imbalance. Excessive vibration and noise. The operational pump is not optimal. To fix it causes operational delay.

- Excessive power consumption: vibration. Pump run is not efficient. Electric overheat motors. To fix it will make operational delay.

- Excessive power resources: Electric overheat motors. To fix it will make operational delay.

- Excessive vibration: damage to other pumps components. The pump will trip. To fix it will make operational delay.

- Gasket failure: water drop through the gasket. Flowrate turns. The pumped cooling water pressure drops so that the pump suction level also falls. The operational pump is not optimal.

- Impeller failure: cause pump efficiency to be low. The pumped cooling water pressure drops so that the pump suction level also falls. The operational pump is not optimal. If the impeller is broken, the cooling water pump trip will break.
- Pressure pulsation: too low at pressure indicator suction \& discharge pressure. To fix it will make operational delay.

- Reduction in pump pressure: the pumped cooling water pressure drops so that the pump suction level also falls. The operational pump is not optimal. To fix it will make operational delay.

- Seal failure: leakage, premature seal failure, damage to shafting \& transmission system. The operational pump is not optimal. To fix it causes the operational delay.

- Shaft failure: excessive vibration, noise, and friction. Damage transmission system. Process train out of service for a time to make the repair.

- Suction and discharge recirculation: Suction \& discharge pressure too high at pressure indicator. To fix it will make operational delay.

\section{d) Making The RCM Decision Worksheet}

For the next analysis process, the author analyzes the analyzes failure consequences and chooses maintenance tasks for each functional failures by answering the RCM Decision Diagram as shown in Figure 4 [1]. In this figure, some terms are found such as:

\section{- Hidden and Evident Functions}

A hidden function is one of which failure will not become evident to the operating crew under normal circumstances if it occurs on its own. Meanwhile, an evident function is one of which failure will on its own eventually and inevitably become evident to the operating crew under normal circumstances. The consequence is separated between hidden functions from evident functions because hidden functions need special handling.

Evident failures are classified into three categories, as follows:

(a) Safety and environmental consequences

A failure has safety consequences if it could injure or kill someone. It has environmental consequences if it could lead to a breach of any corporate, regional or national environmental standard.

(b) Operational consequences

A failure has operational consequences if it has a direct adverse effect on operational capability (total output, product quality, customer service, operational cost of direct repair).

(c) Non-operational consequences

Evident failure in this category affect neither safety or production 


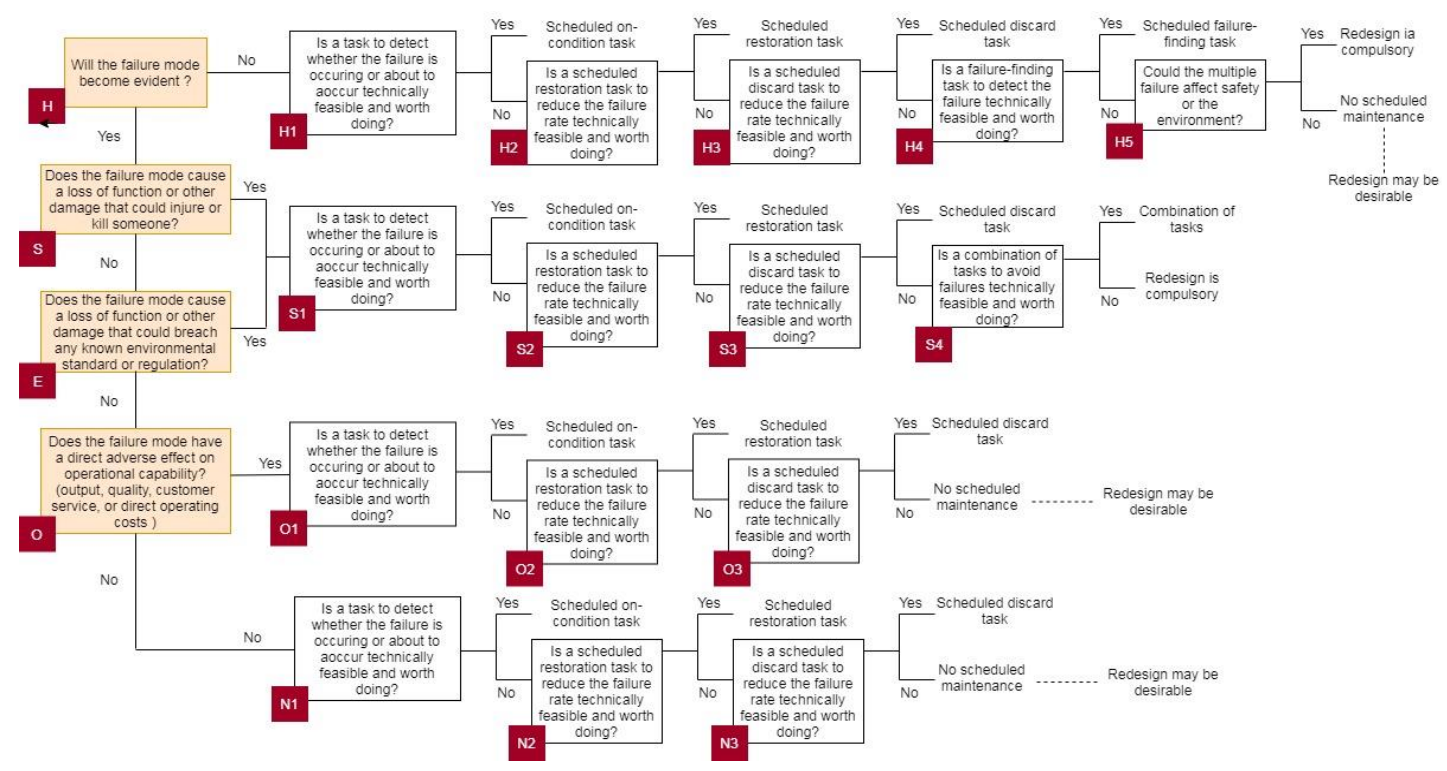

Figure. 4. The RCM decision diagram

\section{- Failure Management Techniques}

Failure management techniques are devided into two categories:

(a) Proactive Task

These tasks must be done before a failure occurs.

(b) Default Actions

These actions are done when there is no proactive task chosen or suitable to overcome the.

\section{- Proactive Tasks}

Like it said before, the proactive tasks are tasks that must be done before the occurrence of the failure. Generally, proactive tasks are called "preventive maintenance" and "predictive maintenance". The proactive tasks can be divided into these following categories:

(a) Preventive Maintenence: Scheduled Restoration Task. It needs to restore the initial capability of the asset before a specified age limit.

(b) Preventive Maintenance: Scheduled Discard Task. It needs to discard or remove the asset at/or before a specified age limit.

(c) Predictive Maintenance: On Condition Task. It needs to check for potential failures, so the action can be taken to prevent the functional failure or to avoid the consequences of functional failure. The potential failure itself is an identifiable condition which indicates that a functional failure is either about to occur or in the process of occurring.

The major categories of on-condition techniques are as follows:

(a) Monitor lubricating oil by taking an oil sample from the production equipment to check the thickness / to see the quality of oil stored in the oil tank.

(b) Visual Monitoring. This method uses senses which include the sense of sight, sense of taste, and a sense of hearing to determine the condition of the engine.

(c) Performance monitoring is a technique in monitoring the condition of the production machine by checking and measuring the performance parameters when compared to the standard.

(d) Geometric monitoring, it is expected that the geometric deviations that occur in the production equipment can be known and can be carried out leveling and alignment measurement activities.

(e) Vibration monitoring, in this monitoring checks and measures the location of vibrations routinely and continuously.

\section{- Default Actions}

The three major categories of default actions are:

(a) Failure-finding. It needs to check the hidden functions periodically to find out whether they have failed or not.

(b) Redesign. It needs to make any one-off change to the built-in capability of a system.

(c) No scheduled maintenance (run-to-failure). It needs to make no effort to prevent failure mode, and so those failures are simply allowed to occur and then repaired.

Other information that supports this step is determining the age-related and non-age-related failure that can be seen in Figure 5. And the how to answer the RCM Decision Worksheet is as follows Figure 6: 


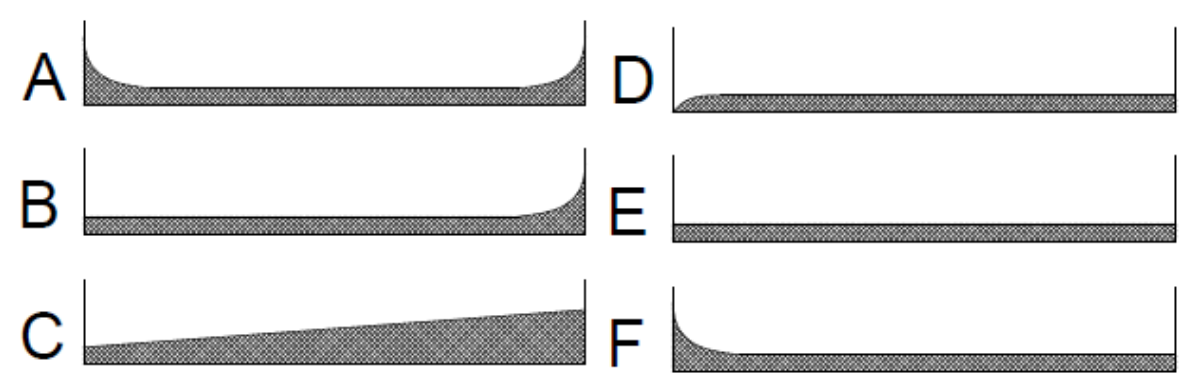

Figure. 5. Failure paterns

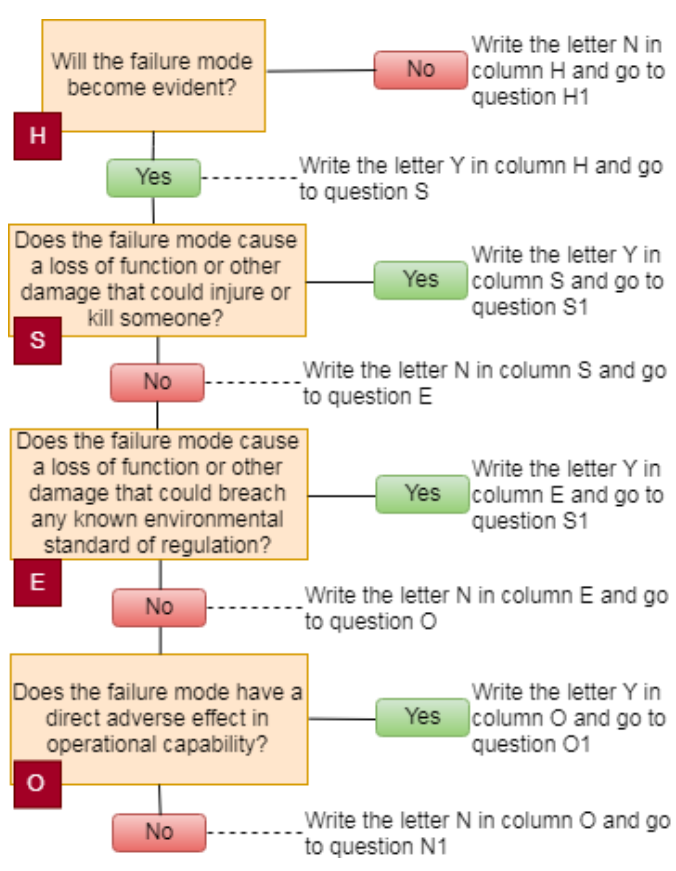

Figure. 6. The way to answer the RCM decision diagram

Here are the steps to generate the RCM Decision Worksheet:

\section{(1) Failure Consequence Analysis}

The author again bases this process on the guidelines given in the RCM Book written by John Moubrey. Whereas if failure consequence has been analyzed, then the next step is to find out whether the pump and its components are possible to perform and actions and proactive tasks that reduce the consequence of failure. The method for selecting maintenance actions can be done by using The RCM Decision Diagram.

\section{(2) Maintenance Task Techniques Selection}

In combining the results of the process of determining the cause of failure with the results of the RCM Decision Diagram will produce the final results in the form of maintenance actions in accordance with the equipment requirements reviewed. The process of determining the cause of failure shows which parts are critical and often causes equipment failures. However, this knowledge is not necessarily useful if it is not known how (the intensity) of repairs can be done and whether the application can be explained, cost-effective and time. By conducting a logic tree analysis, it is obtained how (according to HSEO factors) the intensity of the new maintenance/repair process should be carried out. In other words, it can be determined whether new maintenance measures for equipment (or equipment components) must be carried out with scheduled on-condition tasks, scheduled restoration tasks, scheduled discard tasks, scheduled failure finding tasks, no scheduled maintenance or redesign. As previously mentioned, the RCM output process is a new maintenance action. This maintenance action must be able to eliminate or minimize the consequences of failure. However, so that this maintenance can be applied must be justified in its implementation.

By answering the RCM Decision Diagram and following the steps to make the RCM Decision worksheet, the results that have been made is like Table 1 . 
TABLE 1.

THE RCM DECISION WORKSHEET

\begin{tabular}{|c|c|c|c|c|c|c|c|c|c|c|c|c|c|}
\hline \multirow{3}{*}{ Failure Modes } & \multirow{2}{*}{\multicolumn{4}{|c|}{$\begin{array}{l}\text { Consequence } \\
\text { evaluation }\end{array}$}} & \multirow{3}{*}{\begin{tabular}{|l|}
$\mathrm{H} 1$ \\
$\mathrm{S1}$ \\
$\mathrm{O} 1$ \\
$\mathrm{~N} 1$ \\
\end{tabular}} & \multirow{3}{*}{\begin{tabular}{|l|}
$\mathrm{H} 2$ \\
$\mathrm{~S} 2$ \\
$\mathrm{O2}$ \\
$\mathrm{N} 2$ \\
\end{tabular}} & \multirow{3}{*}{\begin{tabular}{|l|} 
H3 \\
S3 \\
O3 \\
N3 \\
\end{tabular}} & \multirow{2}{*}{\multicolumn{3}{|c|}{$\begin{array}{l}\text { Default } \\
\text { Action }\end{array}$}} & \multirow{3}{*}{ Proposed task } & \multirow{3}{*}{ Initial Interval } & \multirow{3}{*}{ Can be done by } \\
\hline & & & & & & & & & & & & & \\
\hline & H & $s$ & E & 0 & & & & $\mathrm{H4}$ & H5 & 54 & & & \\
\hline Bearing failure & Y & $\mathrm{N}$ & $\mathrm{N}$ & $\mathrm{Y}$ & Y & & & & & & $\begin{array}{l}\text { (Scheduled on-condition tasks) Check and monitor the } \\
\text { vibration bearings. And temperature. Shutdown cooling } \\
\text { water pump. First run C.W Pump which is stand by. } \\
\text { Improve bearing installation. }\end{array}$ & Daily & Operator \\
\hline Blockages & Y & $\mathrm{N}$ & $\mathrm{N}$ & $\mathrm{Y}$ & Y & & & & & & $\begin{array}{l}\text { (Scheduled on-condition task) Install flow meter on } \\
\text { suction and discharge on pump. Cleaning. }\end{array}$ & Daily & Operator \\
\hline Cavitation & $\mathrm{Y}$ & $\mathrm{N}$ & $\mathrm{N}$ & $\mathrm{Y}$ & $\mathrm{N}$ & $\mathrm{N}$ & $\mathrm{N}$ & & & & (No scheduled maintenance) & - & Operator \\
\hline Electric motor failure & Y & Y & & & Y & & & & & & $\begin{array}{l}\text { (Scheduled on-condition tasks) Check safety device of } \\
\text { power consumption. Ensure the power to the drive unit is } \\
\text { correctly installed. }\end{array}$ & Daily & Operator \\
\hline Excessive power consumption & Y & Y & & & Y & & & & & & $\begin{array}{l}\text { (Scheduled on-condition tasks) Monitor temperature, } \\
\text { electricity, vibration, pressure. Ensure the power to drive } \\
\text { the unit is correctly installed. }\end{array}$ & Daily & Operator \\
\hline Excessive power resources & Y & Y & & & Y & & & & & & $\begin{array}{l}\text { (Scheduled on-condition tasks) Check safety device of } \\
\text { power consumption. Ensure the power to the drive unit is } \\
\text { correctly installed. }\end{array}$ & Daily & Operator \\
\hline Electric motor over heat & Y & Y & & & Y & & & & & & $\begin{array}{l}\text { (Scheduled on-condition tasks)Monitor the vibration, } \\
\text { temperature, electricity of standard performance. }\end{array}$ & Daily & Operator \\
\hline Excessive vibration & Y & $\mathrm{N}$ & $\mathrm{N}$ & $\mathrm{Y}$ & Y & & & & & & $\begin{array}{l}\text { (Scheduled on-condition task) Check and analyze the } \\
\text { vibration that occurs. }\end{array}$ & Daily & Operator \\
\hline Gasket failure & $\mathrm{Y}$ & $\mathrm{N}$ & $\mathrm{N}$ & $\mathrm{Y}$ & $\mathrm{N}$ & $\mathrm{N}$ & $\mathrm{N}$ & & & & (No scheduled maintenance) & - & Operator \\
\hline Impeller failure & Y & $\mathrm{N}$ & $\mathrm{N}$ & Y & N & Y & & & & & $\begin{array}{l}\text { (Scheduled restoration tasks) Adjust impeller. On some } \\
\text { action there is no scheduled maintenance, or replace } \\
\text { impeller. }\end{array}$ & Annually & Operator \\
\hline Pressure pulsation & Y & $\mathrm{N}$ & N & Y & N & Y & & & & & \begin{tabular}{|l|} 
Scheduled restoration tasks) Check pressure and flow \\
rate. Install a dampener.
\end{tabular} & Weekly & Operator \\
\hline Reduction in pump pressure & Y & $\mathrm{N}$ & $\mathrm{N}$ & Y & Y & & & & & & $\begin{array}{l}\text { (Scheduled on-condition tasks) Check pressure of suction } \\
\text { and discharge, check leakages. }\end{array}$ & Daily & Operator \\
\hline Seal failure & $\mathrm{Y}$ & $\mathrm{N}$ & $\mathrm{N}$ & $\mathrm{Y}$ & $\mathrm{N}$ & $\mathrm{N}$ & $\mathrm{N}$ & & & & (No scheduled maintenance) & - & Operator \\
\hline Shaft failure & Y & $\mathrm{N}$ & $\mathrm{N}$ & Y & Y & & & & & & $\begin{array}{l}\text { (Scheduled on-condition tasks) Check vibration, } \\
\text { temperature, tightening, lubricating, shaft allignment. } \\
\text { Check up condition of wear and renew them if needed, } \\
\text { Dismantling and replace on certain actions. Check up } \\
\text { condition of contact, flaw in sliding faces, and bend of } \\
\text { shaft. }\end{array}$ & Daily & Operator \\
\hline Suction and discharge recirculatioin & Y & $\mathrm{N}$ & $\mathrm{N}$ & $\mathrm{Y}$ & Y & & & & & & (Schedulen on-condition tasks) Monitor flow \& pressure. & Daily & Operator \\
\hline
\end{tabular}

\section{Results}

From the analysis, the scheduled maintenance tasks result suitable for cooling water pump and related components in one of the LNG production company are:

\section{○ Pump}

- Monitor flow rate of pump suction \& discharge.

- Monitor pressure of pump suction \& discharge.

- Monitor bearing vibration.

- Monitor bearing temperature.

- Monitor motor vibration.

- Monitor motor temperature.

- Monitor motor elecctricity performance.

- Check alignment annually.

- Check impeller adjustment annually

- Check leakage weekly.

- Check nuts and bolts at foundation weekly.

- Travelling screen \& Hayward Strainer

- Monitor differential pressure.

- Monitor temperature at transmission system.

- Check lubrication at transmission system monthly
- Lubrication

- Oil analysis is done every 6 months and replaced every 1 year

- Monitor flow rate at MOP.

- Monitor pressure at MOP.

- Monitor vibrasi at MOP.

- Monitor pressure at LO filter.

- Monitor temperature at LO Cooler.

- Check any leakage weekly.

- Check PCL and respon of AOP annually

- Boving Valve \& Amri Valve

- Check leakage weekly.

- Monitor LO level at reservoir.

- Replace oil every 1 year

- Check pump pressure.

- Monitor pump vibration.

- Check pressure pada filter.

- Monitor motor vibration.

- Monitor motor temperature.

- Monitor motor electricity performance.

- Check pressure of Bladder N2 Gas.

- Replace bladder. 
In addition, from the failure modes analyzed, the maintenance techniques that suitable for cooling water pumps and related components in one of the LNG production company are shown in Figure 7 with the following explanations:

- $28 \%$ of failure modes included in "no scheduled maintenance"

- $5 \%$ of failure modes that are included in the "scheduled discard task"
- $28 \%$ of failure modes that are included in the "scheduled restoration task"

- $38 \%$ of failure modes included in" scheduled on-condition task "

- and 2\% of failure modes that are included in" failure finding: a combination of tasks ".

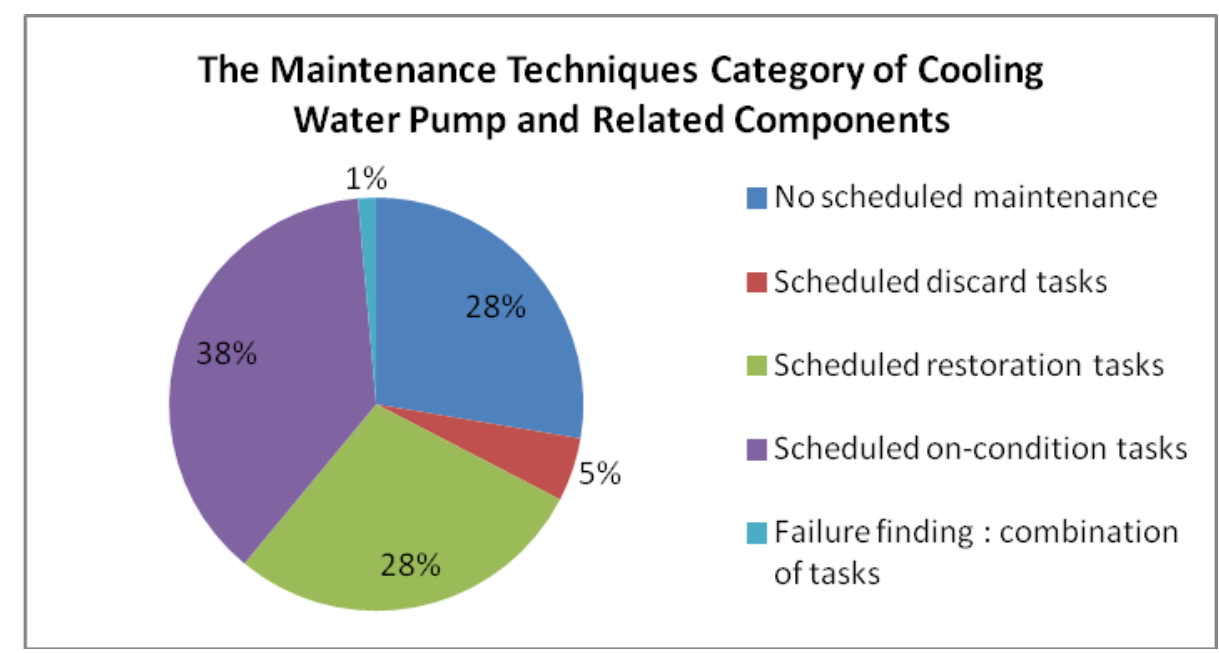

Figure 7. The maintenance techniques category of cooling water pump

\section{CONCLUSION}

According to the analysis of the study obtained, the conclusions for answering any formulation or any problems that have been presented before:

- RCM can be used to make scheduled maintenance.

- From the analysis, the suitable scheduled maintenance tasks that the most widely applied to cooling water pump in one of the LNG production company are scheduled on-condition task which has a percentage of almost $40 \%$ compared to all scheduled maintenance tasks that have been analyzed.

- From the analysis, the reviews of the old RCM with the new RCM obtained from this bachelor thesis result of cooling water pump in are:

- The old RCM instructs to change the lube oil every 2 years, but the new RCM do oil analysis, record it every 6 months and replace oil every 1 year.

- The old RCM instructs no scheduled maintenance of impeller, but the new RCM do scheduled restoration tasks of the impeller by checking adjustment annually.

- The old RCM instructs to check any leakage every 3 months, but the new RCM check any leakage weekly.

- For the suggestion, there are some updates to improve the RCM of the cooling water pump in one of the LNG production company, they are:
- Further data needs to be done by discussing with the crew of PT. Badak LNG regarding RCM results.

- Further data needs to be analyzed by considering the cost aspect.

- Calculate the lifetime of the component if possible to proposed the maintenance initial interval more accurately.

\section{REFERENCES}

[1] J. Moubray, Reliability-Centered Maintenance Second Edition, New York: Industrial Press, 1997.

[2] D. Priyanta, Introduction to RCM Workshop Presentation, Jakarta: Maintenance \& Production Reliability Conference, 2005.

[3] Team Task Force "Pembuatan Plant Operational Manual", Cooling Water \& Fire Pump, Bontang: PT. Badak NGL, 2014.

[4] Dwi Priyanta, M.B. Zaman, Apriagung D.P, "Maintenance Task Allocation and Planning in KT. X Tugboat using RCM Method," International Journal of Marine Engineering Innovation and Research, vol. 2 (1), pp. 59-69, Dec. 2017.

[5] H. P. Bloch and A. R. Budris, Pump User's Handbook: Life Extension Third Edition, London: The Fairmont Press, 2010.

[6] T. C. Dickenson, Pumping Manual, Oxford: Elsevier Science Ltd, 1995.

[7] S. Yedidiah, Centrifugal Pump User's Guidebook, New York: Chapman \& Hall, 1996.

[8] The Barden Corporation, Bearing Failure: Causes and Cures, Connecticut: The Barden Corporation, 2011.

[9] Reliability Analysis Center, "Failure Mode/Mechanism Distributions," IIT Research Institute, New York, 1991. 